\title{
Losartan reduced cardiovascular morbidity and mortality more than atenolol in patients with diabetes and essential hypertension
}

Lindholm LH, Ibsen H, Dahlöf B, et al., for the LIFE study group. Cardiovascular morbidity and mortality in patients with diabetes in the Losartan Intervention for Endpoint reduction in hypertension study (LIFE): a randomised trial against atenolol. Lancet 2002 Mar 23;359:1004-10.

QUESTION: In patients with diabetes, essential hypertension, and signs of left ventricular hypertrophy (LVH), is losartan-based therapy more effective than atenolol-based therapy?

\section{Design}

Randomised (unclear allocation concealment*), blinded (patients and monitoring committee),* controlled trial with $\geq 4$ years follow up.

\section{Setting}

Multicentre trial in Europe and the United States.

\section{Patients}

1195 patients (a predefined subgroup of patients who had diabetes mellitus at the start of the LIFE study) who were 55 to 80 years of age (mean age 67 y, $53 \%$ women) with hypertension (sitting blood pressure [BP] after 1 to 2 wks of placebo of 160 to $200 \mathrm{~mm} \mathrm{Hg}$ systolic, 95 to $115 \mathrm{~mm} \mathrm{Hg}$ diastolic, or both) and electrocardiographical signs of LVH. Exclusion criteria included secondary hypertension; myocardial infarction (MI) or stroke within the previous 6 months; angina pectoris requiring treatment with $\beta$-blockers or calcium antagonists; and heart failure or left ventricular ejection fraction $\leq 40 \%$. Follow up was $100 \%$.

\section{Intervention}

Patients were allocated to losartan based therapy ( $\mathrm{n}=$ 586) or atenolol based therapy $(n=609)$. Losartan and atenolol were started at $50 \mathrm{mg}$ /day, combined with low dose hydrochlorothiazide if needed then increased to $100 \mathrm{mg} /$ day if needed, and supplemented with other antihypertensives (except $\beta$-blockers, angiotensinconverting enzyme $[\mathrm{ACE}]$ inhibitors, or angiotensin- receptor blockers [ARBs]) to reach a target $\mathrm{BP}<140 / 90$ $\mathrm{mm} \mathrm{Hg}$.

\section{Main outcome measures}

The primary end point was a composite of cardiovascular mortality, MI, and stroke. One of the secondary end points was heart failure.

\section{Main results}

Analysis was by intention to treat. The composite end point, cardiovascular mortality, all cause mortality, and heart failure, occurred less frequently in patients assigned to losartan than in those assigned to atenolol.

\section{Conclusion}

In patients with diabetes, essential hypertension, and signs of left ventricular hypertrophy, losartan reduced cardiovascular morbidity and mortality and all-cause mortality more than atenolol.

*See glossary.
Losartan-based therapy $v$ atenolol-based therapy in diabetes with essential hypertension and signs of left ventricular hypertrophy

\begin{tabular}{lrrll} 
Outcomes & Losartan & Atenolol & RRR (95\% CI) & NNT (CI) \\
Composite end point $\neq$ & $18 \%$ & $23 \%$ & $22 \%(2$ to 39$)$ & 21 (12 to 250$)$ \\
\hline Cardiovascular mortality & $6 \%$ & $10 \%$ & $36 \%(5$ to 57$)$ & 28 (18 to 211$)$ \\
\hline All-cause mortality & $11 \%$ & $17 \%$ & $37 \%(15$ to 53$)$ & 16 (12 to 40$)$ \\
\hline Heart failure & $5 \%$ & $9 \%$ & $40 \%(8$ to 61$)$ & 28 (19 to 145$)$ \\
\hline
\end{tabular}

†Abbreviations defined in glossary; RRR, NNT, and $\mathrm{Cl}$ calculated from data in article. ‡Cardiovascular mortality, stroke, and myocardial infarction.

\section{COMMENTARY}

Physicians can become frustrated when prescribing medications for asymptomatic patients with chronic diseases. They may doubt that the benefit of treatment exceeds the cost and risks for side effects. Patients may not comply if the cost or side effects exceed perceived benefits. As a result, therapeutic goals may be difficult to achieve.

The LIFE studies show that potentially life-threatening complications can be reduced with fewer side effects. The original, placebo controlled public health trials of hypertension used thiazides and $\beta$-blockers. These agents successfully reduced cardiovascular disease and stroke; thus, they have been considered first-line treatment for hypertension. ${ }^{1}$ In the LIFE studies, losartan reduced stroke and combined cardiovascular end points to a greater degree than atenolol. The data indicate that cardiovascular protection by using an ARB is superior to that of a $\beta$-blocker for patients with hypertension and LVH, which are independent risk factors for cardiovascular disease. Other trials using ACE inhibitors and ARBs have shown cardiovascular and renal benefits unrelated to their effects on hypertension. ${ }^{2-3}$ We need to reconsider the selection of first-line hypertensive therapy, particularly in patients at high risk.

Several comments should be made concerning the study methodology and results. Most patients required $\geq 2$ agents to reach target level BP, which is consistent with other trials. ${ }^{4}$ Use of multiple agents could confound the comparison between the 2 agents in reducing risk. Lower systolic pressures should have been targeted. The final mean systolic BP was $146 \mathrm{~mm} \mathrm{Hg}$ in patients with diabetes and $144 \mathrm{~mm} \mathrm{Hg}$ in those without. To minimise cardiovascular events, systolic pressure should be decreased to $120 \mathrm{~mm} \mathrm{Hg}$ and $140 \mathrm{~mm} \mathrm{Hg}$ in patients with and without diabetes, respectively. ${ }^{5} 16 \%$ of the patients smoked. No attempt to change dietary, exercise, or smoking habits was noted. Visits were semiannual; more frequent appointments could produce better compliance, lower BP, and more positive lifestyle changes. Aggressive anti-hypertensive therapy, daily aspirin administration, and lifestyle improvements could have further reduced cardiovascular events. 


\title{
Losartan reduced strokes and new onset diabetes more than atenolol in essential hypertension
}

\author{
Dahlöf B, Devereux RB, Kjeldsen SE, et al, for the LIFE study group. Cardiovascular morbidity and mortality in the \\ Losartan Intervention for Endpoint reduction in hypertension study (LIFE): a randomised trial against atenolol. Lancet \\ 2002 Mar 23;359:995-1003.
QUESTION: In patients with essential hypertension and signs of left ventricular hypertrophy (LVH), is losartan-based therapy more effective than atenolol-based therapy?

\section{Design}

Randomised (unclear allocation concealment*), blinded (patients and monitoring committee),* controlled trial with $\geq 4$ years follow-up.

\section{Setting}

Multicentre trial in Europe and the United States.

\section{Patients}

9222 patients 55 to 80 years of age (mean age $67 \mathrm{y}, 54 \%$ women) with hypertension (sitting blood pressure [BP] after 1 to 2 wks of placebo of 160 to $200 \mathrm{~mm} \mathrm{Hg}$ systolic, 95 to $115 \mathrm{~mm} \mathrm{Hg}$ diastolic, or both) and electrocardiographical signs of LVH. Exclusion criteria included secondary hypertension; myocardial infarction (MI) or Source of funding: Merck. stroke within the previous 6 months; angina pectoris requiring treatment with $\beta$-blockers or calcium antagonists; and heart failure or left ventricular ejection fraction $\leq 40 \%$. Follow-up was $99 \%$.

For correspondence: Professor B Dahlöf, Sahlgrenska University Hospital/Ostra, Gothenburg, Sweden. Emailbdahlof@ scandinaviancrise.

\section{Intervention}

Patients were allocated to losartan based therapy ( $\mathrm{n}=$ $4605)$ or atenolol based therapy $(\mathrm{n}=4588)$. Losartan and atenolol were started at $50 \mathrm{mg} /$ day, combined with low dose hydrochlorothiazide if needed and then increased to $100 \mathrm{mg} /$ day if needed, and supplemented with other antihypertensive drugs (except $\beta$-blockers, angiotensin-converting enzyme $[\mathrm{ACE}]$ inhibitors, or angiotensin-receptor blockers [ARBs]) to reach a target $\mathrm{BP}<140 / 90 \mathrm{~mm} \mathrm{Hg}$.

\section{Main outcome measures}

The primary end point was a composite of cardiovascular mortality, MI, and stroke. One of the secondary end points was new onset diabetes.

\section{Main results}

Analysis was by intention to treat. The composite end point, fatal or non-fatal stroke and new onset diabetes, occurred less frequently in patients assigned to losartan than in those assigned to atenolol (table). No difference existed between the groups for cardiovascular mortality or MI. BP control, dose titration, and use of other antihypertensives were similar in both groups.

\section{Conclusion}

In patients with essential hypertension and signs of left ventricular hypertrophy, losartan reduced strokes and new-onset diabetes more than atenolol.

*See glossary.

1 The sixth report of the Joint National Committee on prevention, detection, evaluation, and treatment of high blood pressure Arch Intern Med 1997:157:2413-46. Brenner BM, Cooper ME, De Zeeuw D, et al. Effects of losartan on renal and cardiovascular outcomes in patients with type 2 diabetes and nephropathy. $N$ Engl J Med 2001:345:861-9. Heart Outcomes Prevention Evaluation Study Investigators. Effects of ramipril on cardiovascular and microvascular outcomes in people with diabetes mellitus: results of the HOPE study and MICRO-HOPE substudy. Lancet 2000.355.253-9.

4 Hansson L, Zanchetti A, Carruthers SG, et al. Effects of intensive blood-pressure lowering and low dose aspirin in patients with hypertension: principal results of the Hypertension Optimal Treatment (HOT) randomised trial. Lancet 1998;351:1755-62.

5 Ader AI, Stratton IM, Neil HA, et al. Association of systolic blood pressure with macrovascular and microvascular complications of type 2 diabetes (UKPDS 36 ): prospective observational study. BMJ 2000;321:412-9. 